\title{
REFLEXÕES ACERCA DA CRISE HEGEMÔNICA ESTATAL \\ À LUZ DO FENÔMENO DA GLOBALIZAÇÃO: A EMERGÊNCIA DOS NOVOS MOVIMENTOS SOCIAIS
}

\begin{abstract}
Rafhael Wasserman
Acadêmico do quinto ano diurno da Faculdade de Direito da Universidade Federal do Paraná e bolsista do Programa de Extensão "Núcleo de Direito Internacional da UFPR".
\end{abstract}

RESUMO: O presente estudo tem como escopo a análise do Estado a partir de um dos maiores fenômenos da atualidade, a globalização e consequentemente, o surgimento dos novos movimentos sociais. Isto posto, parte-se para a observação histórica do Estado com o fim de traçar seus elementos fundantes. Posteriormente, traçam-se as características inerentes ao contexto atual de crise da hegemonia estatal, marcada pela incapacidade desse personagem de resolver conflitos surgidos em uma sociedade globalizada. Com o advento da globalização, houve um incremento das relações internacionais, surgindo novas forças em contraposição a estatal, dentre elas as empresas transnacionais e os novos movimentos sociais. Constata-se, pois, a impossibilidade do Estado de lidar com o mundo fenomênico, eis que seus institutos demandam um lapso temporal incompatível com as novas necessidades, realçado o contexto de capitalismo periférico brasileiro.

PALAVRAS-CHAVES: Estado. Crise. Globalização. Transnacionalização. Novos Movimentos Sociais. Monismo. Pluralismo. Dogmática jurídica. Capitalismo periférico. 


\section{NOTAS INTRODUTÓRIAS}

O estudo em tela tem como objeto, os novos personagens sociais surgidos em decorrência de novas demandas da sociedade excluída na globalização. Para tanto, faz-se necessário retornar às origens do Estado. Partindo do pressuposto de que o Estado é fruto do desenvolvimento de um ente que detém o poder centralizado e absoluto, chega-se ao momento atual de crise.

A crise hegemônica pela qual atravessa o Estado possui íntima conexão com o fenômeno da globalização, eis que o movimento globalizante gera novas necessidades e novos personagens. Dentre os personagens criados pela sociedade, voltada para 0 interesse do capital, que, ao mesmo tempo em que prega o neoliberalismo, exclui camadas inteiras de indivíduos, cabe citar as transnacionais, detentores do poder de influenciar as políticas e as economias de países soberanos e os novos movimentos sociais, surgidos da exclusão das populações excluídas da face positiva da globalização, principalmente localizadas em países periféricos.

As empresas transnacionais, como serão analisadas em capítulo oportuno, criam uma nova mentalidade, na qual o antigo é substituído pelo novo e um contínuo inconformismo consumista. Porém, não apenas as transnacionais compõem os novos atores sociais, tendo em vista que, em posição antagônica, se encontram os novos movimentos sociais.

Esses movimentos sociais, distintos de seus antecessores, atuam por meio de táticas diversas, desestabilizando a estrutura estatal. A partir deste contexto que o artigo se posiciona, com o Estado incapaz de encontrar soluções para as questões envolvendo interesses diversos, resultando em uma incapacidade intrínseca aos seus mecanismos internos.

\section{A EVOLUÇÃO DO ESTADO MODERNO E DO PENSAMENTO JURÍDICO ESTATAL}

O presente capítulo procura abordar os fundamentos determinantes do Estado desde seus primórdios, inserindo seus caracteres básicos, permitindo a compreensão do fenômeno jurídico que delineou a sociedade por vários séculos. O sistema só pode ser absorvido a partir da constatação dos fatores que the deram 
causa, como uma relação de causa e efeito. Em decorrência da ideologia preponderante em um dado momento histórico, os demais instrumentos jurídicos, políticos e sociais são afetados, como um encadeamento de fatos unidos por uma teia única de logicidade.

Para tanto, o resgate histórico se mostra inevitável. Essa visão de realidades distintas decorrentes de períodos diversos da história da sociedade e da cultura e obriga o observador a fixar marcos ou termos para iniciar seu estudo. Em face disso, os séculos XVII e XVIII dão o início à jornada que nos propomos quando, advindos da cultura jurídica européia ocidental, a centralização política, o modo de produção capitalista e Estado Nacional Soberano surgiram. ${ }^{1}$

A análise histórica se inicia com o fim do Feudalismo e sua forma de organização social e modo de produção de riquezas, quando houve o esvaziamento dos feudos e conseqüente aumento dos ressurgidos burgos. Percebe-se nesse ponto o surgimento do capitalismo, trazendo uma nova racionalidade e aumento das relações comerciais. O capital se torna, pois, meio pelo qual as riquezas são produzidas, além de constituir, por si mesmo, uma riqueza. ${ }^{2}$

Coadunada com a classe burguesa surgida no seio do sistema feudal, criouse uma cultura que agregava os elementos da racionalidade burguesa e capitalista, - chamado Liberalismo. Essa filosofia servia como justificativa para o desenvolvimento de uma classe média e o comércio recém descoberto. Segundo acepção de Antonio Carlos Wolkmer

(...) o Liberalismo torna-se expressão de uma ética individualista voltada basicamente para a noção de liberdade total que está presente em todos os aspectos da realidade, desde o filosófico até o social, o econômico, o político, o religioso etc. Em seus princípios, o Liberalismo se constituiu na bandeira revolucionária que a burguesia capitalista (apoiada

${ }^{1}$ Porém, antes disso, o sistema preponderante na sociedade era o feudal, marcado por dois aspectos: o fim do escravismo romano e a derrocada da estrutura de poder bárbara. Nesse momento, a propriedade da terra era determinante para a dominação de classes sociais sobre outras, gerando um pluralismo jurídico, uma vez que o poder emanava de diversas fontes, como os nobres, o clero e corporações de ofício. O sistema jurídico, por sua vez, era calcado em uma multiplicidade de fontes e consuetudinário, sujeito aos privilégios das classes superioras.

${ }^{2}$ Não se procura tratar aqui das bases teóricas do capitalismo em toda a sua diversidade, seja capitalismo comercial, industrial e financeiro, ou ainda, mercantil, concorrencial ou monopolista. Basta apenas que seja aclarada a relação existente entre o poder centralizado e o modo de produção capitalista, como se pode atentar pelo silogismo entre ambos e os interesses da burguesia. 
pelos camponeses e pelas camadas sociais exploradas) utiliza contra o Antigo Regime Absolutista. $^{3}$

\section{E continua o professor catarinense:}

Mais tarde, contudo, quando o Capitalismo começa a passar à fase industrial, a burguesia (a elite burguesa), assumindo o poder político e consolidando seu controle econômico, começa a "aplicar na prática somente os aspectos da teoria liberal" que mais lhe interessam, denegando a distribuição social da riqueza e excluindo o povo do acesso ao governo $^{4}$

O Liberalismo possui, em seu âmago, a liberdade dos indivíduos mas, ao mesmo tempo, uma liberdade condicionada, pois apenas aqueles que detém o capital gozam de liberdade plena. ${ }^{5}$ Nada obstante, a burguesia necessitava de segurança para as relações que travava, protegendo seus interesses e resguardando a dominação exercida sobre as demais classes sociais.

O intento foi alcançado com a centralização política, unindo diversos centros independentes sob o mesmo controle, leis e sistemas aduaneiros. Criou-se, pois, um sistema concentrado e unitário. Toda a autoridade foi unificada nas mãos da autoridade estatal, que emanava o direito e exercia a soberania como caractere inerente à sua estrutura, como já propalava Hobbes em seu Leviatã."6 7

\footnotetext{
${ }^{3}$ WOLKMER, Antonio Carlos. Pluralismo Jurídico, p. 38.
}

4 Idem, ibidem.

${ }^{5}$ O Liberalismo observado de forma insular não possui carga valorativa própria, eis que se junta a ele o individualismo. O individualismo liberal se caracteriza, ao expressar a mentalidade burguesa, por colocar 0 homem no centro das decisões, sejam elas políticas, sociais e econômicas.

${ }^{6}$ Com efeito, o termo Estado foi pela primeira vez adotado por Maquiavel em seu livro "O Princípe" e "a denominação Estado (do latim status = estar firme), significando situação permanente de convivência e ligada à sociedade política. (DALLARI, Dalmo de Abreu. Elementos de Teoria Geral do Estado, p. 51).

7 De acordo com as lições trazidas por MICHEL MIAILLE, o Estado reflete o pensamento liberal burguês, eis que: "O Estado aparece com <a realidade em que o indivíduo tem a sua liberdade e goza dela enquanto saber, fé e querer geral.

Ele constitui assim, o elo final de uma cadeia histórica que representa a marcha gradual da evolução do princípio cujo conteúdo é a consciência da liberdade: o Estado reconcilia o particular e o universal dando ao individuo a moralidade objectiva. O Estado é, então, face aos interesses privados, uma necessidade, a que, unindo vontade particular e vontade universal, permite ao homem encontrar uma plena realidade, a do reconhecimento do próprio Espírito" (MIAILLE, Michel. Introdução Crítica ao Direito, p. 126) 
Possuindo conexão lógica com a estrutura do moderno Estado burguês, o Direito era monopolizado pelo Estado, único legitimado para criar normas jurídicas às relações entre os mais diversos entes sociais. ${ }^{8}$

O monismo jurídico, abstrato, geral e impessoal, tem em seus primórdios uma relação umbilical com o capitalismo mercantil, que substitui o sistema feudal, relacionado à monarquia absolutista. ${ }^{9}$

Porém, os interesses envoltos nessa falsa imagem de neutralidade são obscurecidos. Esse Direito, de índole burguesa, tinha como corolário lógico o atendimento aos interesses da classe capitalista, apesar da ressaltada impessoalidade da estrutura jurídica. ${ }^{10}$

Já em um segundo momento, o monismo jurídico será decorrente das ordens emanadas pelo Estado, porém, retirado o papel do soberano. O capitalismo concorrencial, encartado nas relações de poder, demandava um distanciamento do Estado do mercado, abrindo espaço para a burguesia desenvolver suas atividades livremente. O Direito, portanto, seria fruto da vontade soberana do Estado, e não mais da vontade única do soberano.

O moderno Estado burguês ocidental se relativizou, permitindo incursões do capitalismo voltado ao mercado e suas estruturas correlatas. Esse Estado fundou-se na tripartição de poderes, soberania, supremacia da Constituição, democracia representativa formal, direitos civis e políticos. ${ }^{11}$

O Direito passa pelo fenômeno da unificação a partir da Revolução Francesa e o espírito Iluminista e racionalidade jusnaturalista. As codificações surgiram como resposta às necessidades de segurança burguesas, realizando uma sistematização da dogmática jurídica. O Direito estatal passa a aglomerar o poder coercitivo, tornando efetivo o Direito posto.

8 A doutrina monista, portanto, tem como fonte primária o Direito Romano, derrogando o Direito Canônico a sua importância. O Direito era criado único e exclusivamente pelo Estado, ou seja, pelo governante, que possuía o poder de fato.

${ }^{9}$ As leis criadas pelo Estado surgiam dos poderes consagrados por Montesquieu, possuindo abstração e generalidade. Para que as leis percebam a legitimidade necessária para serem observadas, recebem o manto da positivação. Essa legalidade positivada gerava a presunção de obediência por ambos os pólos da relação jurídica, sejam eles cidadãos ou o Estado, eis que a legalidade pretensamente não eivada de vícios permite o surgimento do Estado de Direito. Isto é, o Estado, ao se denominar Estado de Direito e, portanto, observador dos preceitos por ele mesmo definidos, garante a sua soberania.

\footnotetext{
${ }^{10}$ WOLKMER, A. C. Op. Cit. p. 49.

${ }^{11}$ WOLKMER, A. C. Op. Cit, p. 43.
} 
Todavia, no Estado intervencionista, outro fruto do desenvolvimento do Capitalismo, que passa da etapa concorrencial e industrial, para a etapa monopolista/financeira, mudanças são almejadas. O Estado intervencionista está ligado ainda a uma contínua burocratização da administração pública e do assistencialismo em diversas searas. ${ }^{12}$

O Direito nesse período tem como interlocutor a figura de Kelsen, que trouxe para a ciência jurídica o formalismo dogmático. Para ele, o Estado é o próprio Direito, formando um ente só. Para o exercício da função jurisdicional, o Estado deveria utilizar o seu poder coercitivo para se tornar eficaz.

O Estado de Bem-Estar recém surgido, contudo, entra em crise, dando espaço a um processo de desorganização e reorganização do capital internacionalmente. Surgem, pois, as corporações internacionais, blocos econômicos e mercados integrados. Assim, o poder se descentraliza, possibilitando o aparecimento de novos personagens.

No entanto, o Estado brasileiro surge de maneira diversa, não estando relacionado diretamente com o desenvolvimento do capitalismo central, mas com um capitalismo periférico e estranho às transformações das concepções de indivíduos e de Estado típicas da racionalidade européia. A tradição jurídica brasileira, como bem demonstrada por Marcos Augusto Maliska, decorre da herança cultural ibérica semiperiférica, trazendo conseqüências negativas para o surgimento do Estado, como assevera:

A tradição jurídica portuguesa, vinculada à concepção patrimonial de Estado, introduziu no Brasil um Estado deficitário e uma cultura jurídica excessivamente formalista. O Direito e o Judiciário, na época colonial, não construíram a idéia de cidadania. A igualdade jurídica foi sempre uma tentativa de igualdade formal, nunca material. (...)

Deve-se ter presente que o Estado brasileiro não nasce das exigências do cidadão, uma vez que a situação de colônia não permite falar em cidadania. O Estado resulta da transferência de poder real da metrópole para a colônia, que implanta-se burocraticamente, distante da sociedade e alheio a seus objetivos. O domínio burocrático português, que construi o Estado cartorial no Brasil, permitiu a organização de um aparelho burocrático que dificilmente poderia ter-se formado localmente, tendo em vista o atraso cultural que

\footnotetext{
12 Idem, p. 44.
} 
comprometeu a formação da colônia. Nesta época, no Brasil, tem-se o Estado como tutor da sociedade e como representante do poder do Príncipe. ${ }^{13}$

A partir dessa formação do Estado em âmbito mundial e mais especificamente no Brasil, tem-se que os entes soberanos não conseguem dar conta das situações demandadas pelos indivíduos integrantes da sociedade como um todo, gerando uma crise estrutural.

\section{A CRISE DA ESTRUTURA HEGEMÔNICA ESTATAL}

A crise do Estado advém da incapacidade de atender às necessidades de seus partícipes, além de falhas em relação à representação política. A crise decorrente dos erros dos representantes políticos ocasionou um processo de desilusão generalizado, perda da legitimidade, com a falência da democracia regida pela participação por meio de representação política.

As atividades exercidas pela sociedade obrigam, pois, a construção de um novo paradigma, segundo a moldura epistemológica fundada por Kuhn, cuja função seria de solucionar a crise burocrática e a falta de moral dos servidores do Poder Público.

Atualmente, a sociedade se encontra inserida em um movimento unificador e globalizante, com a derrubada das barreiras entre os Estados soberanos. O Direito passa a existir fora da esfera do Estado, enterrando o positivismo jurídico que refletia uma sociedade burguesa moderna. O monismo jurídico servia apenas para a manutenção do poder e cultura burguesa, garantindo as diferenças entre as classes sociais, como leciona Wolkmer:

Entretanto, esta supremacia representada pelo estatismo jurídico moderno, que funcionou corretamente com sua racionalidade formal e serviu adequadamente às prioridades institucionais por mais de dois séculos, começa, com a crise do Capitalismo monopolista e a conseqüente globalização e concentração do capital atual, bem como com o colapso da cultura liberal individualista, a não mais atender o universo complexo dos sistemas organizacionais e dos novos sujeitos sociais. Evidencia-se o descompasso de uma estrutura normativista, gerada em função de valores e interesses, que sofre incisivas modificações paradigmáticas e não mais retrata os inteiros objetivos das condições de vida presentes. As atuais sociedades de massa integrantes do centro e da periferia capitalista passam por

\footnotetext{
${ }^{13}$ MALISKA, Marcos Augusto. Pluralismo Jurídico e Direito Moderno, p. 25.
} 
novas e flexíveis modalidades de produção do capital, por radicais contradições sociais e por instabilidades continuadas que refletem crises, tanto em nível de legitimidade, quanto de produção e aplicação da justiça. ${ }^{14}$

Essa crise representa o momento histórico pelo qual a sociedade passa atualmente. Verifica-se, pois, um momento de mudanças, cultivadas pelo advento de uma nova racionalidade e quebra dos paradigmas precedentes. O sistema jurídico estatal não é mais capaz de dar conta das relações sociais atuais. Como demonstra Michel Miaille:

(...) ○ Estado não é, como afirmam implicitamente os juristas, uma categoria eterna que decorra logicamente da necessidade de assegurar uma ordem; é um fenômeno histórico, surgido num dado momento da história, para resolver as contradições aparecidas na sociedade civil $^{15}$

Há a necessidade de redefinir o papel do Estado, pois os sistemas antes empregados para uma sociedade estruturada em classes sociais separadas por um abismo, se provaram insuficientes ante as novas demandas. As promessas impossíveis pregadas pelo capitalismo, que seriam a panacéia para a população não se realizaram. Como aduz Wilson Ramos Filho há na sociedade:

uma descrença generalizada no Estado e em seus instrumentos característicos de participação, os partidos políticos, em face da impossibilidade de realização da promessa capitalista, desconfiança esta agudizada nos setores populares pela incapacidade do Estado em solucionar questões básicas para o atual estágio civilizatório como moradia, escola, saúde, saneamento básico, etc.

Este descrédito não se limita ao Estado, mas se generalizou em desconfiança ante a todas as instituições, inclusive nos sindicatos e nos partidos políticos de esquerda. Isso traz, dentre outras, a conseqüência de gerar a compreensão quase que generalizada do anacronismo da forma atual de Estado. ${ }^{16}$

Essa crise desencadeada pelas incapacidades do Estado de prover as necessidades da população é agravada pelo fenômeno da globalização, que traz mudanças substanciais nas relações políticas, econômicas e sociais. Os Estados

\footnotetext{
${ }^{14}$ WOLKMER, A. C. Op. Cit. p. 69/70.

${ }^{15}$ MIAILLE, M. Op. Cit. p. 128.

${ }^{16}$ RAMOS FILHO, Wilson. Direito Pós-Moderno: Caos Criativo e Neoliberalismo, p. 82.
} 
passam a sofrer a perda de seu monopólio de coerção, com o surgimento de mecanismos supranacionais, criando interligações entre Estados soberanos e afetando as suas hegemonias.

Os Estados periféricos, por sua vez, são atingidos de várias maneiras pela crise surgida pela incapacidade estatal. Diz-se isso tendo em consideração a dependência econômica que esses países possuem em relação aos países mais ricos. Não obstante isso, como se verá a seguir, além da pressão exercida pelos demais países, observa-se atualmente os mecanismos coercitivos das empresas transnacionais advindos do movimento globalizante.

Os países da América Latina e no nosso caso, o Brasil, possuem grandes diferenças sociais, decorrentes da má distribuição de riquezas entre seus cidadãos. Assim, há uma outra pressão decorrente das estruturas sociais localizadas fora da esfera estatal, que procuram obter seus direitos e obter soluções para seus problemas, criticando a regulação capitalista bem como a emancipação social socialista.

\section{O FENÔMENO DA GLOBALIZAÇÃO}

A temática relativa à globalização é lugar-comum em muitos textos jurídicos ou não-jurídicos concernentes à contemporaneidade. Contudo, em face das mudanças substanciais causadas pelo fenômeno, se provou inescusável tratar do referido tema.

A globalização, porém, não possui apenas uma acepção, mas muitas. Desde a percepção de sua natureza econômica, política, social, cultural até a jurídica, possui diversos mecanismos de interligação e comunicação nas relações internacionais. Segundo define Fernando Augusto Knoerr, a globalização seria "uma crescente interconexão em vários níveis da vida cotidiana a diversos lugares longínquos no mundo". ${ }^{17}$ Já para Ney José de Freitas, a globalização consistiria em "um movimento complexo de aberturas de fronteiras econômicas e de desregulamentação, que permite às atividades econômicas capitalistas estender seu campo de ação ao conjunto do planeta" ${ }^{18}$

\footnotetext{
17 KNOERR, Fernando Gustavo. Representação Política e Globalização, p. 152.

${ }^{18}$ FREITAS, Ney José de. Globalização, Neoliberalismo e Direito do Trabalho, p. 215.
} 
O fenômeno gerou efeitos em diversas searas, criando dificuldades para desenhar novos modelos teóricos capazes de solucionar a crise de paradigmas trazida à tona pela quantidade de mudanças observadas nestes últimos anos. Como bem adverte José Eduardo Faria sobre o fenômeno objeto de estudo:

transnacionalização dos mercados de insumos, produção, capitais, finanças e consumo (...) transformou radicalmente as estruturas de dominação política e de apropriação de recursos, subverteu as noções de tempo e espaço, derrubou barreiras geográficas, reduziu as fronteiras burocráticas e jurídicas entre nações, revolucionou os sistemas de produção, modificou estruturalmente as relações trabalhistas, tornou os investimentos em ciência, tecnologia e informação em fatores privilegiados de produtividade e competitividade, criou novas formas de poder e influencia novas e autônomas e, por fim, multiplicou de modo exponencial e em escala planetária os fluxos de idéias, conhecimento, bens, serviços, valores culturais e problemas sociais $(\ldots)^{19}$

Contudo, esse fenômeno não é novo. De fato está presente, mutatis mutandis, desde o surgimento do homem, pois o ser humano sempre almejou ultrapassar as fronteiras estabelecidas, alcançando campos outrora inexplorados, seja enquanto um homem primitivo ou homem do século XXI.

Não obstante, no que tange aos efeitos da globalização na esfera estatal, houve a relativização do conceito de soberania, antes absoluto. Nesse sentido, leciona Fernando Augusto Knoerr:

Com o advento da globalização econômica, podemos constatar a crise ou declínio do Estado-Nação, decorrente da transnacionalização da economia implementada pelo fenômeno da globalização econômica, respaldada pela teoria econômica do neoliberalismo, em face da gradual erosão da soberania, da obsolência das fronteiras nacionais, do retraimento da esfera pública em favor do mercado e da perda dos direitos políticos dos cidadãos como resultado do esvaziamento da sua participação política. ${ }^{20}$

Nesse cenário, emergem os blocos econômicos, estes voltados à integração entre seus países-membros. Como assevera Ney José de Freitas, "A idéia de Estado como nação passa a ser substituída pela concepção de blocos de nações e

\footnotetext{
${ }^{19}$ FARIA, José Eduardo. O Direito na Economia Globalizada, p. 13.

${ }^{20}$ KNOERR, F. G. Op. Cit. p. 155.
} 
até de um mundo global com um "Estado Único" como se houvesse benefício ou progresso para todos de forma linear."21

Os novos personagens da atual configuração mundial, protagonistas desse capítulo na história, são as transnacionais. Isto porque, exercem seu poder e diminuem a esfera de atuação do Estado, impondo seus interesses acima das necessidades dos países envolvidos. Esses personagens são responsáveis, pois, por realizar transações internacionais movimentando, em sua grande maioria, valores acima da arrecadação de países inteiros. Assim, ditam suas condições para o estabelecimento em dado país, podendo ser, desde impostos à mão-de-obra. ${ }^{22}$

Dessa forma, como conseqüência direta do fenômeno, houve a despolitização ou naturalização da produção. Como aduz Boaventura de Souza Santos:

As guerras econômicas deixaram de ter lugar entre Estados nacionais para passarem a ter lugar entre blocos ou entre devedores nacionais e credores internacionais. Os Estados nacionais, sobretudo os periféricos e semiperiféricos, foram sendo postos na posição de ter de competir entre si pelas contrapartidas, quase sempre leoninas, susceptíveis de atrair investimento das empresas multinacionais. ${ }^{23}$

Além disso, a concentração de capital nas mãos de empresas transnacionais e conglomerados de natureza financeira geram outros efeitos, eis que o capital circula em investimentos de curto prazo, cujo objetivo é gerar lucros o mais rápido possível, fora do espaço restrito do território nacional, impossibilitando ao Estado controlar esse fluxo.

Não obstante, permite-se fazer referência à situação enfrentada pelos países periféricos, como os localizados na América Latina, já que nesse caso, por possuírem economias dependentes ao capital internacional e transnacional, se mostram mais vulneráveis ainda a manipulações do jogo econômico. Assim, advém o refletido por Antônio Carlos Wolkmer ao descrever a situação de países como o Brasil:

${ }^{21}$ FREITAS, N. J. de. Op. Cit. p. 224.

22 A "difusão social da produção", termo utilizado por Boaventura de Souza Santos, traduz a fragmentação do trabalho, resultando em conflitos entre mercados de trabalho pelo investimento externo, advindo das empresas transnacionais.

${ }^{23}$ SANTOS, Boaventura de Souza. Pela Mão de Alice, p. 251. 


\begin{abstract}
"A expansão da economia capitalista intensifica a sangria dos mercados dos países pobres e amplia as desigualdades de intercâmbio do comércio mundial, restringindo à América Latina a mera função de exportadora de produtos primários e importadora de capital e tecnologia. Constantemente, a conjuntura do capital imperialista central se recompõe e articula novas formas de intervenção (os "ciclos" do Capitalismo) no espaço de dependência dos países periféricos" 24
\end{abstract}

Compete observar que o Estado e o mercado passam a se relacionar de maneira distinta, sejam eles periféricos ou centrais, não mais resguardando a soberania estatal, mas uma conjugação entre o poder político do Estado e os novos detentores do poder econômico. Não há mais um centro de decisões localizado no cerne do Estado, uma vez que o capital está difuso em vários centros em Estados diversos. ${ }^{2526}$

Além disso, o tempo do capitalismo também se modifica e diminui, demandando uma redução radical no lapso temporal necessário para a conclusão do litígio. Parece claro, por conseguinte, que há um abismo entre o tempo das relações comerciais internacionais e o tempo da decisão judicial pela via estatal. Além disso, há incompatibilidades entre o tempo da economia atual e a democracia, tendo em vista o tempo despedido entre os setores sociais competentes para obter uma solução ou para o Estado modificar seu ordenamento em relação ao tempo do mercado mundial. ${ }^{27}$

Assim, o Estado, que antes solucionava todos os conflitos através do Judiciário, se servindo do papel de árbitro necessário, encontra dificuldades para exercer a outrora absoluta função. A Jurisdição estatal não é mais capaz de abranger todas as hipóteses de litígios na sociedade atual, globalizada, na qual emergem novos movimentos sociais, dentre eles, os já citados conglomerados econômicos mas também os novos movimentos sociais, explorados na seqüência.

\footnotetext{
${ }^{24}$ WOLKMER, A. C. Op. Cit. p. 80.

25 Esses centros difusos de emanação de decisões são responsáveis pela produção de tecnologias novas e eficientes em substituição de outras criadas por eles mesmos, mas que para a lógica globalizante não são mais úteis.

${ }^{26}$ A perda da soberania e aumento do poderio das empresas transnacionais não significou, contudo, um incremento dos mecanismos de solução de conflitos em escala mundial. O poder do Estado foi substituído por um aumento do poder das referidas empresas em uma relação inversamente proporcional, porém, sem o devido aumento do poder de pacificação dos litígios tendo como mediador as transnacionais. Isto é, a perda da capacidade dos Estados de solucionar conflitos não foi ocupada por uma presumida posição das empresas transnacionais de ocupar esse lugar.
} 


\section{OS NOVOS ATORES SOCIAIS}

A incapacidade estatal de resolver os conflitos inerentes à sociedade contemporânea e o surgimento dos novos atores sociais, a seguir expostos, simboliza a crise dos fundamentos e paradigmas do Direito atual. A Dogmática Jurídica não mais possui soluções para os problemas sociais. Por isso, provou-se inadequada a estrutura estatal, cabendo encontrar outro referencial para a sociedade do século XXI, marcadamente globalizada. Os países localizados na periferia mundial, por sua vez, sofrem uma crise exacerbada, conseqüência da incapacidade do Estado de resolver seus conflitos em face da desorganização e corrupção inerentes aos seus quadros burocráticos.

Os novos atores sociais, como os organismos empresariais, os blocos econômicos, os grandes conglomerados econômicos e seus antagonistas, os movimentos sociais tradicionais e os novos movimentos sociais, traduzem as forças políticas e sociais que influenciam no estágio atual da sociedade em escala mundial.

Permite-se tratar das forças sociais que se contrapõem à dominação capitalista, os movimentos sociais tradicionais e com maior atenção, os novos movimentos sociais. Contudo, há diferenças substanciais entre as duas figuras, eis que os últimos pressupõem uma estrutura não hierarquizada e com composição heterogênea, atuando em locais específicos, ao contrário dos movimentos sociais tradicionais, como os sindicatos e partidos de massas, que possuem uma certa homogeneidade e alto grau de burocracia.

Os novos movimentos sociais surgem em diversas épocas da história brasileira, notadamente nas décadas de 70, 80 e 90. Esses movimentos contrariam a tradição capitalista liberal de identidade do sujeito, visto de maneira isolada. $O$ contexto de sociedade periférica, reflexo da dominação de Estados de cultura semiperiférica e dependente do capital externo, propiciou o aparecimento dos novos movimentos sociais, de caráter emancipatório, em busca de uma nova identidade.

Os novos movimentos sociais provêm de fatores extrínsecos e intrínsecos ao Estado brasileiro. Fatores esses que causaram a modificação do entendimento dos líderes dos novos movimentos sociais que se distanciaram de seus antecessores. A população brasileira, em suas camadas mais humildes, percebeu a

\footnotetext{
${ }^{27}$ RAMOS FILHO, W. Op. Cit. p. 90.
} 
falência das instituições estatais que ocasionaram a diminuição da qualidade de vida dos cidadãos, aliada à falta de segurança nas instituições políticas, claramente suscetíveis à corrupção.

Outros fatores que merecem atenção dos estudiosos do Direito dizem respeito à união de esforços dos cidadãos, com escopo de garantir qualidade de vida mínima, sofrendo largamente devido à incapacidade estatal de prestar serviços básicos inerentes ao seu papel.

No que tange à influência do capital externo no país como elemento causador do surgimento dos novos movimentos sociais, vale transcrever passagem de Marcos Augusto Maliska:

O surgimento dos movimentos sociais, a partir da metade da década de 70 , é fortemente influenciado pela necessidade de melhorar a qualidade de vida, principalmente, em se tratando de movimentos urbanos de periferia nas grandes cidades. A diminuição da qualidade de vida nos grandes centros urbanos é resultado do crescimento não planejado das cidades. Este crescimento teve como agravante a invasão industrial das multinacionais no pós-64, que inviabilizou de tal forma a vida dos habitantes dos subúrbios, que se tornou necessária a organização desses moradores para que conseguissem os serviços públicos básicos. $^{28}$

A política no período ditatorial brasileiro privilegiou a utilização de capital estrangeiro para a industrialização do país, ampliando as diferenças entre classes sociais. Isto porque, com o acúmulo de empresas e indústrias no país operando um aumento da tecnologia no sistema de produção ocorreu um aumento e posterior e diminuição da oferta de empregos, inflando os grandes centros urbanos que se provaram incapazes de recepcionar os novos habitantes.

Desse modo, comprova-se a influência do movimento transnacional, globalizante, para o surgimento dos novos movimentos sociais, de forma antagônica. O fenômeno da globalização, que possibilitou o aumento das relações entre os mercados como um elastecido espaço de influência para os grandes conglomerados, contribuiu para o surgimento dos novos movimentos sociais, como um efeito indesejado.

${ }^{28}$ MALISKA, M. A. Op. Cit. p. 69. 
Cabe citar a contribuição de Abili Lázaro Castro de Lima, que demostrou a incapacidade do Estado em atuar para propiciar direitos fundamentais aos seus cidadãos, como pode ser observado:

Assim, o papel do Estado não seria mais aquele ligado à atenuação das desigualdades do mercado ou, como concebia Marshall, atinente a garantia da liberdade e igualdade de oportunidades dos indivíduos com a garantia de condições dignas de bem-estar social que possibilitassem a participação dos cidadãos nos destinos da sociedade. O novo papel do Estado seria garantir e proteger "a ordem expontânea" instituída pelo livre mercado.

Em outras palavras, na medida em que ocorre a diminuição do papel do Estado, consoante o receituário neoliberal, podemos verificar que o poder Estatal se desvanece em prol do poder das empresas transnacionais e organismos internacionais, e que a esfera pública deixa de tutelar os direitos sociais, fazendo com que eles gradualmente se dissipem. $O$ fenômeno da globalização desenvolve um processo no qual o espaço público deixa de ser legitimado pela política passando a legitimar-se pela economia. ${ }^{29}$

Assim, o Estado contemporâneo propiciou o campo de atuação para os novos movimentos sociais, que trouxeram a política para dentro da sociedade civil, algo que antes era indesejável, motivando o desenvolvimento emancipatório dos sujeitos, como uma experiência coletiva. O sujeito coletivo deu oportunidade aos indivíduos insularmente concebidos a tomarem consciência da sua posição e lutar pelos seus direitos negados, portanto, valorizando a dignidade da pessoa humana como fim último.

Conforme o pensamento de Antônio Carlos Wolkmer, o novo sujeito coletivo ultrapassa o seu antecessor, caracterizado em uma visão generalizante e que atendia aos objetivos do pensamento burguês:

Assim, a nosso ver, o ‘antigo sujeito histórico' individualista, abstrato e universal, que na tradição da periferia latino-americana vinha sendo representado, dentre tantos, por oligarquias agrárias, setores médios da burguesia nacional, por elites empresariais e por burocracias militares, deve dar lugar a um tipo de coletividade política constituída, tanto por agentes coletivos organizados, quanto por movimentos sociais de natureza rural (camponeses sem terra), urbano (sem-teto), étnica (minorias), religiosa (comunidades eclesiais de base), estudantil, bem como comunidades de mulheres, de bairros, de fábricas,

29 LIMA, Abili Lázaro Castro de. Globalização Econômica Política e Direito. Análise das mazelas causadas no plano político-jurídico, p. 318/319. 
de corporações profissionais e demais corpos sociais intermediários semi-autonômos classistas e interclassistas. $^{30}$

Esses novos atores sociais devem ser compreendidos, como define o professor, em: "sujeitos coletivos transformadores, advindos de diversos estratos sociais e integrantes de uma prática política cotidiana com certo grau de "institucionalização", imbuídos de princípios valorativos comuns e objetivando a realização de necessidades humanas fundamentais."

Os novos sujeitos buscam uma identidade diversa da propagada pelo pensamento liberal-burguês, através da contestação da hegemonia estatal. Nesse ponto, se aproximam de um dos efeitos da globalização, eis que as empresas transnacionais contestam, de forma indireta, a mesma hegemonia estatal. Vale dizer que, ao se observar com granus salis essa proposição, o Estado estaria sendo atingido em dois flancos ao mesmo tempo, isto é, pelo grande capital e pelos que não possui nenhum capital.

Contudo, deve-se considerar essa afirmação até certo ponto, pois as empresas transnacionais estão voltadas para a acumulação de capital, enquanto que os novos movimentos sociais buscam apenas a reivindicação de direitos básicos. Assim sendo, ao almejar lucros e respostas do Estado para as suas próprias demandas, as transnacionais retiram a atenção para os problemas das camadas mais pobres da população que se posicionam como meros espectadores perante a impotência estatal para lidar com seus problemas.

\section{ATUAÇÃO DOS NOVOS MOVIMENTOS SOCIAIS}

Os novos movimentos sociais buscam, por meio de diversos mecanismos de oposição, contestar o Estado, tornando-o seu alvo preferencial em suas ações sociais. Nesse sentido, balizam um movimento emancipatório, transformador da sociedade, incluindo em seu âmago valores esquecidos, como o respeito pelos direitos dos excluídos. Para tanto, o movimento coletivo se manifesta como conjuntos de sujeitos que criam e recriam suas próprias vidas, não mais se atendo a uma posição passiva e meramente observadora.

${ }^{30}$ WOLKMER, A. C. Op. Cit. p. 213 
Além disso, os novos movimentos sociais, ao se dirigirem contra o Estado para que esse se direcione na tomada de alguma decisão relevante, utilizam táticas como dificultar o próprio funcionamento da máquina pública. O Estado, por sua vez, tende a solucionar os conflitos o mais rapidamente possível, para restabelecer o status quo. Caso a solução para o impasse seja de fácil solução, o Estado procura extingui-lo o mais rapidamente, evitando o desgaste político dos administradores públicos. Porém, quando o conflito tende a ser de difícil solução, a tática da transformação do conflito social para um conflito jurídico é iminente. ${ }^{32}$

A partir desse momento, o conflito passa a ser travado no âmbito do Judiciário e, por conseguinte, atravessa todas as fases da processualística pátria. Porém, como o conflito tende a perder o interesse até alcançar o momento da derradeira decisão do magistrado, tem-se observado a utilização de instrumentos antecipatórios da tutela, como medidas cautelares e liminares, porém, somente quando o interesse se voltar às classes dominantes e não aos hipossuficientes.

Para evitar a decisão judicial, o Estado procura fragmentar o conflito, como outra tática de solucionar de forma célere o incômodo, através da responsabilização dos líderes dos movimentos sociais. Utiliza-se, pois, repressão e negociação, atomizando o conflito.

Os novos movimentos sociais, através da autocomposição, com ou sem negociadores, buscam uma solução que seja de seu interesse. Caso não seja alcançado esse escopo pela autocomposição, passa-se a outra fase, a heterocomposição, na qual o Estado atua no conflito pelo Judiciário.

Os movimentos sociais, já antevendo a lentidão acarretada pela solução judicial, prorrogam a primeira fase, seja por desconfiança do Judiciário ou para evitar remédio que não seja de seu agrado. Durante essa fase primeira, de mobilização, os movimentos sociais utilizam negociadores ou não, para estrategicamente compor um melhor acordo. Nada obstante, com o intento de evitar a repressão das forças estatais, atuam através de táticas desmoralizantes. ${ }^{33}$

No entanto, a forma costumeira adotada para obter a solução dos conflitos se dá por meio de negociações com certa dose de imposição, v.g., a invasão de

\footnotetext{
${ }^{31}$ WOLKMER, A. C. Op. Cit. p. 123

32 RAMOS FILHO, W. Op. Cit. p. 100.

${ }^{33}$ RAMOS FILHO. W. Op. Cit. p. 102.
} 
terras improdutivas pelo MST para forçar a desapropriação. Somente por meio de impasses obtêm-se soluções, uma vez que o Estado não possui capacidade para resolver os problemas antecipadamente e tampouco instrumentos para canalizar as reivindicações. ${ }^{34}$

Os participantes do conflito social apresentado devem obter soluções eficientes para suas demandas fora da esfera de atuação do estatal.

Assim, alternativas devem ser focadas, como transações entre as classes excluídas e o capital, na linha seguida pelos movimentos sociais anteriores, como acordos coletivos de trabalho.

Nesta toada, cabe citar as novas relações entre os movimentos sindicais e o capital para escapar da lentidão da esfera burocrática estatal e assim, criar o direito para a força de trabalho. Procura-se, hodiernamente, negociar entre patrões e empregados a partir de acordos coletivos, afastando a atuação do Estado como mediador do conflito trabalho/capital. ${ }^{35}$

Outrossim, os novos movimentos sociais necessitam de instituições não formalizadas, flexíveis e permeáveis para que possam desenvolver suas atuações, fora do manto de jurisdição estatal. Como pode ser aduzido das sugestões de Antônio Carlos Wolkmer, as já existentes formas de mediação e conciliação precisam ser radicalizadas, alargadas e socializadas. Não basta pensar na conciliação a partir do projeto burguês já formado, porém devem ser preservados os atributos que favorecem a participação dos movimentos sociais no Judiciário, que tangenciam os trâmites burocráticos e onerosos da Justiça. ${ }^{36}$

O professor continua definindo o que seria o novo conceito de conciliação:

Desta feita, pode-se e deve-se pensar em "conciliação" como instância de jurisdição completamente informalizada e utilizada a serviço tanto dos sujeitos sociais quanto da

${ }^{34}$ Idem, p. 103.

${ }^{35}$ Faremos uma ressalva, contudo, a partir da visão de Boaventura de Souza SANTOS quanto à perda do papel central do Estado, que não relega a ordem jurídica estatal ao exílio:

La ideologia y la práctica del liberalismo económico impulsada por fuerzas políticas domésticas e internacionales, combinadas con las prácticas de las ETN, han llevado ciertamente a una pérdida relativa del papel protagónico del Estado-nación dentro del sistema mundial. (...)

La pérdida del papel central de la acción estatal en algunas áreas (relaciones laborales, bienestar social) puede, por tanto, coexistir con la recuperación de ese papel en otras áreas (entrenamiento laboral, vigilancia política, ajusde de la política exterior a las operaciones de las ETN). (SANTOS, B. de S. La globalizacion del Derecho, p. 43).

${ }^{36}$ Wolkmer ver pag 
comunidade como um todo. (...) O critério que deve nortear a "conciliação" extra-oficial, como ruptura e alternativa à justiça formal do Estado, não está na aplicação da lógica fundante da atual legislação positiva, mas em novo tipo de interpretação emancipatória, norteada pela legitimidade de novas identidades sociais e firmada na equidade, na ordenação dos justos interesses e na satisfação plena das necessidades humanas fundamentais. $^{37}$

Não obstante, o autor cita outras formas de solução para as limitações estatais, como a criação de "júris populares criminais", "juizados comunitários de pequenas causas", "juntas itinerantes", dentre outros. Os sujeitos coletivos, portanto, consolidariam a sua posição jurisdicional e de fiscalização, legitimando os interesses da sociedade excluída.

O Judiciário, e o Estado, como um todo, não está em condições de solucionar os problemas de maneira eficaz, apenas tomando medidas protelatórias. Para os novos movimentos sociais (como para as empresas transnacionais, citadas anteriormente), as soluções para os problemas precisam ser céleres, cabendo ao Estado estruturar soluções. Contudo, para escapar do monopólio estatal de jurisdição e de juriscriação, é necessário eleger vias alternativas como a proposta pluralista de Direito. Cotidianamente observa-se o oposto, em especial no Brasil, com o Direito Estatal utilizando mecanismo de repressão para aniquilar os novos movimentos sociais, faltando instrumentos para alcançar uma solução eficaz.

\section{CONSIDERAÇÕES FINAIS}

O Estado atual se encontra em franca crise, gerada pelas relações travadas entre os vários personagens sociais existentes na atualidade. O Estado visto como soberano, único legitimado a exercer o poder legiferante e detentor do monopólio jurisdicional está em franca decadência. Isto porque os seus institutos não estão sintonizados às demandas da sociedade globalizada, uma vez que esta requer soluções para seus conflitos que o Estado é incapaz de prover.

As empresas transnacionais ocupam posição de destaque em âmbito mundial, como se pode observar diariamente, seja pela influência que exercem na

\footnotetext{
${ }^{37}$ WOLKMER, A. C. Op. Cit. p. 310.
} 
economia, política, cultura etc, em todos os Estados ou até mesmo nos meios de comunicação que acabam servindo como divulgadores da cultura transnacional.

Hodiernamente, outros atores sociais possuem destaque nas relações sociais, cabendo destacar os novos movimentos sociais. Estes, como as empresas transnacionais, forçam o Estado a obter soluções para seus problemas de maneira ágil e eficiente, incompatível com o exercício de Jurisdição estatal. Deve-se pois, encontrar outros mecanismos de solução de conflitos alheios a esfera de atuação do Estado, bem como modificar a estrutura estatal para que não seja apenas uma máquina sem qualquer utilidade. O Estado se provou impossibilitado de resolver os conflitos inerentes às classes empobrecidas, que não conseguem obter o mínimo dos seus direitos fundamentais garantidos constitucionalmente.

O presente estudo procurou abordar, por meio de um retrospecto histórico em uma reflexão a partir do fenômeno da globalização, os novos movimentos sociais, decorrentes da situação de abandono das políticas de bem-estar. Os integrantes dos novos movimentos sociais expõem as mazelas da sociedade globalizada que procurou esquecer parcelas representativas da população, mas que, ao mesmo tempo que representam grande quantidade numérica, esse número é inversamente proporcional à quantidade de capital em suas mãos. Contudo, esses atores sociais demandam soluções rápidas do Estado para solucionar seus conflitos e a classe governante não pode se furtar a não atendê-los. O fenômeno das Organizações Não-governamentais (ONG) também surge no mesmo contexto aqui abordado, mas seu estudo será objeto de outro trabalho, tendo em vista as limitações deste espaço. 


\section{BIBLIOGRAFIA}

COELHO, Luiz Fernando. Saudades do Futuro. Florianópolis: Fundação Boiteux, 2001.

DALLARI, Dalmo de Abreu. Elementos de Teoria Geral do Estado. 22를 Edição. São Paulo: Saraiva, 2001.

FARIA, José Eduardo. O Direito na Economia Globalizada. São Paulo: Malheiros, 2002.

FREITAS, Ney José de. Globalização, Neoliberalismo e Direito do Trabalho, in: FONSECA, Ricardo Marcelo. Repensando a Teoria do Estado. Belo Horizonte: Fórum, 2004.

KNOERR, Fernando Gustavo. Representação Política e Globalização, in: FONSECA, Ricardo Marcelo. Repensando a Teoria do Estado. Belo Horizonte: Fórum, 2004.

LIMA, Abili Lázaro Castro de. Globalização Econômica Política e Direito. Análise das mazelas causadas no plano político-jurídico. Porto Alegre: Sérgio Antônio Fabris, 2002.

MALISKA, Marcos Augusto. Pluralismo Jurídico e Direito Moderno. Curitiba: Juruá, 2000.

MIAILLE, Michel. Introdução Crítica ao Direito. 2ª Edição. Lisboa: Editorial Stampa, 1994.

RAMOS FILHO, Wilson. Direito Pós-Moderno: Caos Criativo e Neoliberalismo, in: Direito e Neoliberalismo. Ensaios para uma leitura interdisciplinar. Curitiba: EDIBEJ, 1996.

SANTOS, Boaventura de Souza. O Discurso e o Poder. Porto Alegre: Fabris, 1988.

La Globalización del Derecho. Bogotá: UNIBIBLOS, 1998.

Pela Mão de Alice. 4ํㅡㄹ Edição. São Paulo: Cortez, 1997.

WOLKMER, Antonio Carlos. Pluralismo Jurídico. 3ª Edição. São Paulo: Editora Alfa Omega, 2001. 